\title{
Sparkly Princess Shoes: A Case Study Examination of a Social Hierarchy Among Preschool Aged Girls
}

\author{
Jill M. Raisor,a, Ilfa Zhulamanovab, Gina Berridge ${ }^{\circ}$
}

Received
Revised
Accepted
DOl

26 February 2021

19 April 2021

7 June 2021

10.26822/iejee.2021.215

Corresponding Author: Jill M. Raisor.

Department of Teacher Education, Early Childhood

University of Southern Indiana, Evansville, USA.

E-mail: jmraisor@usi.edu

ORCID: http://orcid.org/0000-0003-3333-4237

bllfa Zhulamanova. Department of Teacher Education, Early Childhood, University of Southern Indiana, Evansville, USA.

E-mail: izhulamano@usi.edu

ORCID: http://orcid.org/0000-0002-3167-3289

'Gina Berridge. Department of Teacher Education University of Southern Indiana, Evansville, USA E-mail: ggberridge@usi.edu

ORCID: http://orcid.org/0000-0003-2437-5942

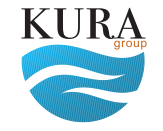

Copyright (c)

www.iejee.com

ISSN: 1307-9298

(C) 2021 Published by KURA Education \& Publishing. This is an open access article under the CC BYNC- ND license. (https://creativecommons.org/ licenses/by/4.0/)

\begin{abstract}
Young children are faced with the challenges of collaborating with others usually for the first time as they enter preschool. They must learn to think beyond their own needs and recognize the needs and wants of other children. Most educators soon realize that the naturally occurring interactions among the children tend to establish hierarchies. A qualitative case study completed over a span of five months examined a clique of five preschool aged girls who appeared to partially identify themselves by wearing what they titled, "sparkly princess shoes". Methods of data collection include interview and observation. Implications for practice and strategies for adults working with preschool aged children are provided.
\end{abstract}

\section{Keywords:}

Peer Relations, Hierarchies, Social Cliques, Socialization, Preschool

\section{Introduction}

Early childhood provides a time of critical growth in Eall developmental domains and it is well understood that play has an important role in both learning and development. Copple and Bredekamp (2009) reiterate the importance of the early learning years and the role of play by stating "the collaborative planning of roles and scenarios and the impulse control required to stay within the play's constraints develop children's self-regulation, symbolic thinking, memory, and language - capacities critical to later learning, social competence, and school success" (p. xiii). Clearly, the skills learned during early childhood provide a foundation for later competencies in many domains. Preschool is the first time that many children are exposed to large numbers of peers outside of their home (Fabes, Martin, \& Hanish, 2009); thereby, creating an ideal time to observe the formation of social hierarchies and the dynamics of social interactions of young children. Peer groups can offer a unique opportunity for a young child to learn how to negotiate his or her space within the group while under the supervision of adults. Martin, Fabes, Hanish, and Hollenstein (2006) claim that the unstructured play-based activities often found in preschools offer a unique opportunity to 
study children's social organization since preschool is often the first time that many young children have the opportunity to interact with same-aged peers on a daily basis.

In this study, children were observed in their natural setting and informally interviewed as situations occurred. The researcher sought to see how social hierarchies are displaced in early childhood classrooms and to what extent are the roles interchangeable or consistent. Also, important are the roles gender-oriented and how is power and/or authority established and maintained? The guiding research question was: How are social hierarchies displayed in early childhood classrooms? Additional research questions explored were: To what extent are the roles in the hierarchy interchangeable or consistent? In what ways, if at all, are the roles genderoriented? And, how is power or authority established and maintained? The following manuscript details findings involving preschool aged girls which were part of a larger study (Raisor, 2010).

\section{Theoretical Framework}

Vygotsky's sociocultural theory emphasizes the importance of increased peer play interaction to enhance cognitive development. When children are involved in peer play the social environment influences cognition through its tools. Vygotsky (1978) believed children develop the tools (i.e. skills) and social rules which lead to cognitive advancement through a process referred to as internalization (Hartup, 2009). Vygotsky's emphasis was on the importance of shared experiences in the acquisition of mental processes, claiming that the social context is actually part of the developmental and learning processes (Bodrova \& Leong, 2007). Bodrova and Leong (2007) agree on the important role that the social context plays in development, claiming that without the shared experience the child could not internalize or independently use higher mental processes.

Social hierarchies can be seen across species and cultures resulting in some individuals having more influence than their peers and better access to all kinds of resources including a mate (Fiske, 1991). As young children begin understanding the organization of their social world and develop in the context of peer relations, they use the information to navigate their social world in strategic ways (Thomsen, 2019). As social structures begin to form some of these peer relations lead to the formation of social hierarchies. "Children's social categories provide a window into the abstract theories they use to make sense of a highly complex social world" (Rhodes, 2012, p. 4). However, these social categories can also include stereotyping and prejudice attitudes in young children (Rutland, Killen, \& Abrams, 2010). "Findings within developmental science show that children develop moral principles of fairness and equality from an early age, but they also develop implicit and explicit prejudice toward others from different social groups" (Rutland, Kellen, \& Abrams, 2010, p. 288). In a seminal mixed methods study, Farver (1996) examined the relationship between preschoolers' aggressive behavior and their social groups and discovered that dominance hierarchies existed among children as young as four. The study found that preschool aged children tended to form reciprocated friendships with children that were similar to themselves in terms of aggression, behavioral style, and social competence. Farver suggested that toughness was often the determinant of social status among preschoolers and defined it as, "the ability to direct the behavior of others, leadership in play, and physical coercion" (p. 335). Farver suggested that teachers should be aware of existing dominance hierarchies in their classroom since lower status children tend to look at higher status children for leadership.

The development of social hierarchies among young children is emerging in educational research. Currently, there is demand for more research in understanding social cliques and a particularly pressing need for qualitative studies. There have been some interesting studies looking at the relationship of gender and group hierarchical behavior. There is a growing body of research that suggests that in terms of aggressive behaviors, males tend to be more physically aggressive and girls more relationally aggressive (Crick, Ostrov, Burr, Cullerton-Sen, Jansen-Yeh, and Ralston (2006); Ostrov and Keating (2004); Giles and Heyman (2005) and that children will be gender-specific when applying either (Giles and Heyman, 2005). In a 2009 longitudinal study, Murray-Close and Ostrov observed the forms (relational vs. physical) and functions of aggression (reactive or proactive) and found that the forms of aggression employed by young children are consistent, but the functions are situational.

\section{Methodology}

Due to limited language skills and concern over the validity and reliability of young children's responses, the qualitative method of observation is most commonly utilized (Ostrov \& Crick, 2007). The research described in this study fills multiple gaps in the existing literature. First, it is a qualitative study where children were observed in their natural setting and informally interviewed as situations occurred. Qualitative research is critical because it allows observational and interview data to capture the actual interactions and conversations of the children while the incidents are occurring in the children's natural play setting. Qualitative research invites the children's perspective to be captured in an age appropriate manner. Second, the research questions investigated the form of social 
structures, the frequency of social interactions, the relation of gender to the roles identified, and power among one set of preschool aged children.

The present case study (Stake, 1995) took place at an early childhood setting on the campus of a large research-intensive university. To maintain anonymity of the setting, the location is referred to as The Center and referenced with the generic citation *The Center. It is located in a rural, Midwestern college town. This site was intentionally chosen because of its proximity to the university and openness to research. The Center provides developmentally appropriate child care for children ages six weeks through approximately five years of age ( ${ }^{*}$ The Center).

The research was conducted in the preschool classroom, commonly referred to as pre-kindergarten or Pre-K. The pre-kindergarten classroom was selected because it is during the preschool years that increased peer interaction occurs (Power, 2000) and is usually the first time that young children are exposed to a large number of peers outside of the home (Fabes, R. A., Martin, C. L., \& Hanish, L. D. (2009). They must learn to think beyond their individual needs and recognize the needs and wants of other children in cooperative play. Peer group interaction provides opportunities for young children to collaborate with others and learn imperative social skills such as cooperation and negotiation.

The children in this study could choose where to play as well as the peers with whom they chose to interact during long periods of play. This freedom contributed to the qualitative nature of the present study by encouraging choice and natural interactions among the children. The Center provided a desirable location for this research through its openness to research, physical arrangement, goals, philosophy, and child centered approach to early childhood education.

The participants in the present study included children ages $3 \frac{1}{2}$ half to 6 enrolled in the pre-kindergarten classroom at The Center. Parental consent was gained from the participant's guardians as well as assent from the children participants. At the beginning of the study, the morning session included 14 children with nine full time children and five children enrolled in half-time care, one of which is enrolled in half-time care on Tuesdays and Thursdays only. The afternoon session consisted of 13 children with nine children in full day care and four children in half-day care. Two new children joined the class in January and were asked to join the study as participants. The total number of children participants was 16; however, one child was not included in the reported data due to lack of attendance in the mornings. This child typically arrived just as first author was exiting The Center. Refer to Table 1 for demographic information on the children included in the study.
Table 1

Demographic Information on Children Participants

\begin{tabular}{lrrr}
\hline Pseudonym & ${ }^{*}$ Age & Gender & Race and/or Ethnicity \\
\hline Alisha & 4.6 & F & Caucasian \\
Angela & 4.7 & F & Caucasian \\
Anne & 3.6 & F & Caucasian \\
Andy & 3.6 & M & Caucasian \\
Austin & 3.1 & M & Caucasian \\
Jackson & 4.6 & M & African American \\
John & 3.5 & M & Asian/Caucasian \\
Julie & 4.1 & F & Chinese \\
Luke & 4.1 & M & Caucasian \\
Kian & 5 & M & Middle Eastern \\
Zavian & 3.6 & M & Middle Eastern \\
Sarah & 4.1 & F & Ethiopian \\
Stephanie & 6 & F & African American/Cauca- \\
& 4.6 & F & Caucasian \\
Tracy & 3.9 & F & Middle Eastern/ \\
Brooke & 4.10 & F & Hispanian \\
**N/A & & &
\end{tabular}

The Center's core staff members only (i.e. Director, prekindergarten Master Teacher, and two Lead Teachers) were included as participants in the research. Assistants, student workers or student teachers were not included in this study or only identified by their role. Refer to Table 2 for demographic information on the core staff members. Some staff members change every eight to 16 weeks; therefore, only the staff that consistently worked with the children through the span of the study were selected for interview.

\section{Table 2}

Demographic Information on Core Staff Participants

\begin{tabular}{lrr}
\hline Age & Gender & Race/Ethnicity \\
\hline 27 & F & Caucasian \\
31 & F & Caucasian \\
32 & F & Caucasian \\
38 & F & Caucasian \\
\hline
\end{tabular}

In order to protect the confidentiality of the participants, pseudonyms are used in all reported data. All core staff members are referred to as core staff for the purposes of this study. All student teachers are referred to as student teachers (ST) while all student workers and practicum students are referred to as student workers (SW).

Methods of data collection included interview with the children participants, observations, and interviews with the adult participants. Observational field notes were simultaneously collected and analyzed for emergent codes. After the observations had concluded, semi-structured 


\section{iejee $\approx$}

interviews were conducted with The Center's prekindergarten core staff members. The interviews were analyzed for contextual understanding, confirmation of the data, and additional adult perspectives of the children's social interactions.

Multiple methods of data collection were utilized including observations, and semi-structured interviews with the pre-kindergarten children and their teachers (Master and Lead) as well as the Director. As stated by Maxwell (2005), interviews and observations often complement each other's validity. "Interviews can provide additional information that was missed in observation, and can be used to check the accuracy of the observations....triangulation of observations and interviews can provide a more complete and accurate account than either could alone" (p. 94). In addition to field notes, the children were randomly assigned numbers (see Table 3) for use in the time samples.

Table 3

Assigned Pseudonym and Number

\begin{tabular}{lr}
\hline Pseudonym & Number \\
\hline Jackson & 1 \\
Julie & 2 \\
Sarah & 3 \\
Andy & 4 \\
Anne & 5 \\
Stephanie & 6 \\
Tracy & 7 \\
Luke & 8 \\
John & 9 \\
Kian & 10 \\
Angela & 11 \\
$*$ & 12 \\
Alisha & 13 \\
Brooke & 14 \\
Austin & 15 \\
Zavian & 16 \\
\hline
\end{tabular}

Note: ${ }^{*}$ Child who was a participant, but not included in the reported data due to lack of attendance.

\section{Observations}

The time samples (refer to Figure 1) were calculated every 30 minutes. The numbers were used to identify where the children were located in the classroom and with whom, if anyone, they were interacting. The single numbers indicate that the child was engaged in solitary play. Two or more numbers together symbolize the group structure (i.e. dyadic, triadic, quad, or five or more children). The daily time samples (refer to Figure 1) were totaled each month to track the areas with the most social interaction as well as which children were playing together. Over the course of the study, 182 time samples were conducted. A spreadsheet of time samples totaling all five months of data was compiled to determine overall patterns in the children's choice(s) of play partners.

\section{Figure 1}

Time Sample

\section{9:30AM}

\begin{tabular}{ll}
\hline Dramatic play area & 4,5 \\
Dramatic play area on rug & 13,15 \\
Block area & $2,7,11$ \\
& 9,10 \\
Activity Table & 16 (Mr. Potato Head) \\
& 14 (dog activity)
\end{tabular}

Library area

Writing Center

Art Center

Sensory table

Loft

Outside

Other:

1, 3, 6, 8 (walking around)

Due to the mobility of the children and The Center's open door policy, only the areas of interaction inside of the classroom were documented. Anytime the children were outside, they were noted with tally marks as outside and their individual interactions were not documented. In addition, the category of other refers to times when the child or children were casually walking around, engaged in project work outside of the classroom, using the restroom, or at an area not categorized for the study, such as on a walk

\section{Interviews}

Interviews are important methods of gaining an understanding of the interviewee's perspective. Not only are the interviewee's responses valuable, but also his or her body language, hesitations or pauses in responses, as well as tone and pacing all add value to data collection during an interview. Bodgan and Biklen (2007) claim "Good listening usually stimulates good talking" (p. 107). Interviews with the children were recorded through field notes and/or audio taping. All interviews, relevant to this study, with the children were transcribed. Quotes were captured and the children's actual language as much as possible in play scenarios and through the use of the audio recorder when allowed.

The interviews with the core staff members were conducted at the end of the observations for fear that the questions might change the interviewees' interactions in the classroom if they were to know in advance the preliminary findings. One Master and two Lead Teachers were interviewed as well as the Director of The Center the week immediately following the end of observational data collection. 
Data analysis occurred in three distinct phases as outlined by Miles and Huberman (1994). The first phase of analysis consisted of uploading and then analyzing transcriptions from her field notes and interviews with the children to identify emergent codes into the computer software, Atlas.ti. The second phase included pattern coding which consisted of the codes being sorted into clusters and creating memos in an attempt to make sense of the data. During the third phase, contextual examples and quotable quotes were pulled from the transcriptions. The process of data analysis assisted in reducing the data to a manageable amount which then led to the emergent themes as well as answers to the research questions.

\section{Results}

The findings of this study identified one established social hierarchy within the preschool classroom. It consisted of three girls, all age four, reported using pseudonyms. The hierarchy is explained in Figure 2 and supporting documentation is detailed in the paragraphs below.

\section{Figure 2}

Small Scale Hierarchy

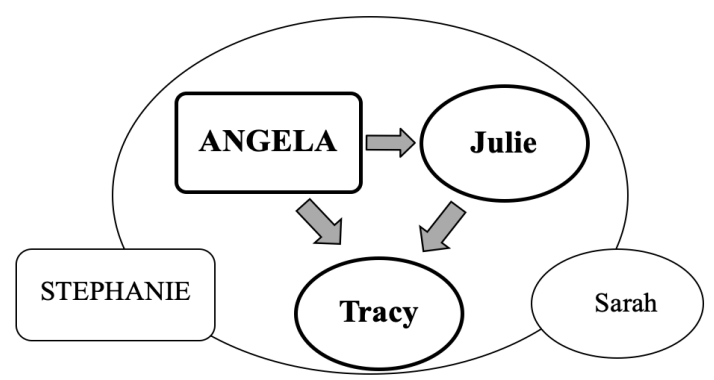

KEY:

\begin{tabular}{|l|l|}
\hline$\square$ & LEADER \\
\hline$\bigcirc$ & Member \\
\hline Large Outer Circle & Enclosed Members \\
\hline$\square$ & Relationship \\
\hline$\triangle$ & Secondary Relationship \\
\hline
\end{tabular}

Note. Based on data from the time samples, observations, interviews with the children and staff this illustrates a consensus of the established hierarchical formation displayed.

\section{Established Hierarchy}

Members: Julie, Tracy, and Angela. ANGELA and Julie displayed a strong dyadic relationship. ANGELA, Julie, and Tracy displayed the strongest triadic relationship observed. ANGELA was identified as being more directive, assertive, or a leader. All three of the girls shared in an exclusive friendship as illustrated by the large outer circle enclosing the members. Stephanie (6) is bi-racial, age 6, and was identified as a floater in and out of the hierarchy by the first author and three of the core staff members. Sarah (3) is Ethiopian, age 4.1, and is an occasional member in the hierarchy as identified by the first author and two of the core staff members. However, she also maintains relationships with children outside of the hierarchy.

\section{Structure: Established Hierarchy}

The strength of the triadic relationship between Julie, Angela, and Tracy was evident and the positioning of Stephanie and Sarah in the hierarchy was clearly displayed. In an example of a student worker attempting to their enter play, the power structure of the hierarchy was evident. The student worker joined the art center and started to join the girls in making cards, when Julie said, "You are not a card maker. You are supposed to ask Angela." The student worker then asked Angela, "Can I please make a Valentine card?" The student worker was granted temporary acceptance in the hierarchy based on the condition set forth by Angela, "Yes, only if you don't bother us." Another example came from the dramatic play area on the rug, when the children were playing babies. Stephanie was informally interviewed immediately after the play inquiring about her role. Stephanie stated, "I was the mom of Sarah." She was asked, "Who decided that?" Stephanie responded, "Them" as she pointed to the art center area. When probed for clarification, she responded, "Who is 'them'?" Stephanie replied, "Angela."

As evidence of occasional acceptance into the established hierarchy, when discussing the seating arrangement at lunch, Julie stated, "She [Stephanie] always wants to sit by me...But, I do not know why." When asked "Well, do you let her sit by you?" And Julie responded, "Well, sometimes." The floater status of Stephanie was described in the field notes as "I noticed that Angela and Julie were playing on the rug. Stephanie was going back and forth between the dramatic play area on the rug and the dramatic play area." In first author's opinion, Stephanie was clearly split between the groups of children playing in different areas of the classroom.

Sarah was identified by first author and two core staff members as a child who floats in and out of the established hierarchy as well. She would occasionally engage in play with the girls inside the hierarchy, but would also maintain her friendships outside of the hierarchy. This balance was evident in an excerpt from the children's play with farm animals.

Sarah: $\quad$ Mommy, mommy I am back. I met a new friend, goat.

Angela: Hello, little goat.

Sarah: Look. 


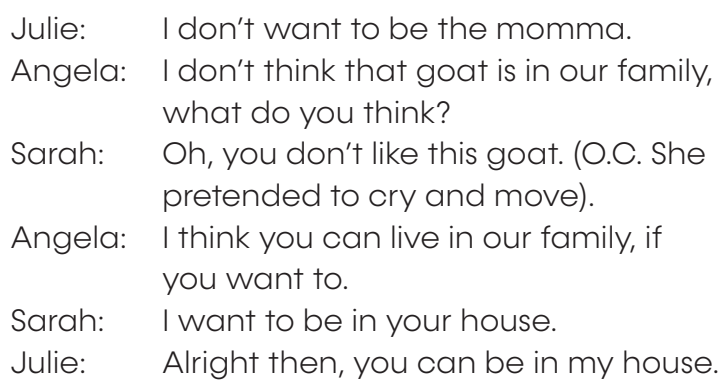

This is a clear example of Sarah attempting to gain entry into the hierarchy's exclusive circle through the use of animals in play. She was able to successfully gain entry and continue play with the girls.

Sarah: Look at me, Julie and Angela!

Core Staff: Julie and Angela, Sarah would like you to look at her.

Angela: We are not playing that.

Angela: Julie, are you playing this with Sarah?

Sarah: I want to play. What can I be?

Although the roles within the small scale hierarchy remained at primarily equal status, often anyone attempting to enter, as an equal, would be redirected by Angela, Julie or Tracy to parallel play, assigned a role of lower status, or rejected from playing. Of interest, children outside of the established hierarchy identified the girls as being friends and often perceived Julie and Angela as their own friends.

\section{Core Staff Perspectives}

A core staff member lent support to the notion of Stephanie as a floater by stating that she, "kind of floats between the grouping of Julie, Tracy, and Angela. Kind of floats in between there and Sarah and Brooke." Another core staff member described "a couple of girls that like to group together" as "... Julie, sometimes Stephanie, Angela, and Tracy..." Articulating Stephanie's floater status, another core staff member said, "Stephanie, I think, kind of just goes in and out of groups as she feels like it."

Two of the core staff members suggested that when Stephanie enters the hierarchy of Angela, Julie, and Tracy that Angela tends to back away from the leadership role. One core staff member stated, "When it is just Julie, Tracy, Angela playing together, Angela tends to be more of the assertive one except when Stephanie enters and she kinds of backs off that." To further first author's understanding of this dynamic, another core staff member explained, "If Stephanie was in any group she would want to be the boss of everyone. She is dominant. She is the oldest child in that room."
One core staff member identified Angela, Julie, and Sarah as children who tended to play together. When asked for confirmation of the triad, "You think that these three [Angela, Julie, and Sarah] females..." and the core staff member interjected "tend to stick together...especially those [Angela and Julie] two." This provided support of Sarah's status as a floater in the hierarchy. A second core staff member mentioned that Julie, Angela, Sarah, and Tracy play together frequently. Another core staff member stated that Sarah, "kind of goes with the flow with lots of different groups. You will see her with the boys, Jackson and Luke in particular. You will see her with the girls [Julie, Angela, Tracy, and sometimes Stephanie] who do a lot of literacy activities as well."

\section{Conclusions}

Two themes emerged from the data. The first theme, The Power of Exclusiveness, was documented in the functioning of the small scale hierarchy. Manners in which the members established their exclusive sisterhood are described. The second theme, The Power of Exclusion, was observed as the small scale hierarchy evolved into an established hierarchy and is detailed in the following paragraphs.

\section{The Power of Exclusiveness}

Each member within the small scale hierarchy of Julie, Angela, and Tracy had a unique way of establishing and maintaining power. Within the clique, each girl was held in primarily equal status whether it was through a primary or secondary relationship. Further, the girls continuously expressed concern about being fair with each other. An example of their concern over fairness was documented as the girls were engaged in cooperative play in the block area. The cohesiveness of the girls was dependent upon them being equal and fair with one another. So, when Angela chose a deer, in the excerpt below, it disrupted the notion of equality. Julie reacted by reinstating the concept of fairness by removing the deer figure and Angela did not display a reaction because she was aware of the rules to their group play. The following excerpt provides evidence of their concern for equality.

Angela: Okay, you guys are really not playing with me.

Julie: You have to come down here and play with us.

Tracy: I am the mom which one do you want to be? (O.C. Angela chooses a deer figure.)

Julie: We all have one that is not fair. (O.C. Julie grabs one of the deer out of Angela's hand and tosses it back into the pile of animal figures. Angela did not say or do anything). 
Another example of the children's concern over fairness came when a student worker made two Valentine cards while at the art center. The student worker asked "Who wants one in their cubbie?" Tracy held up her hand and responded "I do!" Angela said, "Me! Me! Hey, Julie needs one too." The girls took each other's feelings into consideration and found ways to remain fair to each other.

\section{Displays of Sisterhood}

Each girl had a unique way of establishing power within the small scale hierarchy, but this did not necessarily result in authority over another member. Refer to Figure 2 to see an illustration of their small scale hierarchical relationship. For example, one might tend to play the mother role thereby establishing her own form of power, but also displaying a bond of sisterhood by engaging in roles that were consistently equal in status such as sisters, twins, or babies. Field notes provide multiple accounts of this. For example, Julie was documented as saying "Me and Angela are twins! We are the same person." This notion of sameness is consistent with Vygotsky's (1978) idea of how children make a concerted effort to display their relationship while in play. Vygotsky recalled two sisters playing imaginary sisters. Suddenly, the children are conscious of the emphasis of everything being the same to visibly display their relationship of sisterhood. They might dress alike, talk alike, or wear the same clothing to outwardly display their sisterhood. The actions of being sisters might be witnessed in everyday life, but the children bring the unspoken rules of sisterhood to life in their play. Julie and Angela made their bond of sisterhood very clear through their actions, words, and play behaviors.

\section{Figure 3}

Photo of Princess Sparkly Shoes

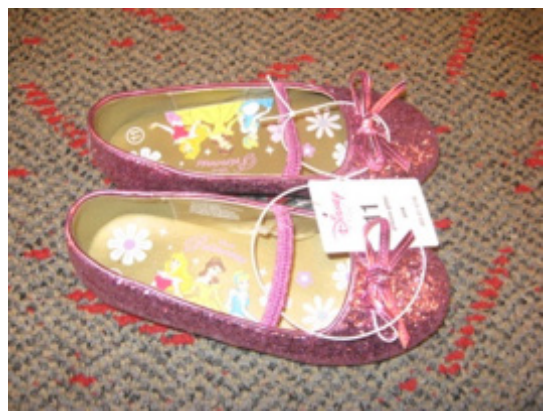

Princess Sparkly Shoes. Another manner in which the small scale hierarchy of girls displayed the exclusiveness of their sisterhood was evident by the members of the hierarchy wearing what they referred to as princess sparkly shoes. Three of the girls within the small scale hierarchy were able to identify the children in the class, Julie, Angela, Tracy, and Sarah, as the children who wear the shoes. The girls were also able to recall that Julie was the first one to get the shoes.

The shoes and what it meant to have a pair sparked particular interest, so Julie and Angela were asked what would happen if someone else in the classroom were to purchase a pair. The following conversation is documentation of Julie and Angela's responses.

First author: Does anybody else in this classroom have them?

Julie: No.

First author: What would you do if one of the other girls got them? Would that be okay or not okay?

(O.C. Angela and Julie both instantly shook their heads no without consulting each other first.)

Julie: Not okay

First author: Why?

Julie: $\quad$ Because we just want our friends and Stephanie is not our friend.

This documentation provides evidence that, at least to the girls, the shoes exhibited a sense of cohesiveness among the members whom they refer to as friends. A core staff member was asked if she had ever heard the girls discussing the shoes. She commented that she had heard, "'I have the pink shoes you don't' or 'we all have the pink glittery princess shoes."' Further she commented, "It has not gotten to the point where it has been upsetting for other children." However, the shoes were a clear indication of the exclusiveness of the girls, at least within the hierarchy. It is speculated that the girls had the shoes because they liked them and wanted to be similar to each other; however, they did not make a big deal of the shoes, maybe in order to keep it a sort of secret bond among them.

According to previous documentation from interviews with the core staff, Stephanie tended to float in and out of the established hierarchy. While in the hierarchy, she often tried to dominate the other children which tended to cause conflict. When Stephanie was asked about the shoes, she responded:

First author: Stephanie, do you know those pink shoes that some of the girls wear, they are pink and they are glittery? Do you know what I am talking about?

Stephanie: I don't know what you are talking about.

First author:You don't know which ones.

Stephanie: Which ones?

First author:Well, they are pink, slip on, and glittery.

Stephanie: Oh, they are Julie's. 


\section{iejee}

First author:Does anyone else have them?

Stephanie: Angela.

First author:Anyone else?

(O.C. No response.)

First author:Do you have a pair?

Stephanie: Yeah. But I didn't want to wear them.

First author:Oh, do you ever wear them to school?

Stephanie: No.

First author: Why not?

Stephanie: Because they are too glittery. So everybody will see them.

Although Stephanie claimed not wear the princess sparkly shoes to school because "everybody will see them," two possible scenarios are suspected. The first is that Stephanie might not really own the shoes and is claiming she does in an attempt to be similar to the other girls. The second possibility is that by wearing the shoes it would associate Stephanie with a hierarchy of which she is not a full member. Therefore, she claims to be the same as the other girls, yet does not feel the need to outwardly display her sameness.

The Power of Exclusiveness was a powerful bond within the small scale hierarchy of girls. The cohesiveness among the girls also led to the second emergent theme, The Power of Exclusion, as a function of the established hierarchy and is detailed in the following paragraphs.

\section{The Power of Exclusion}

The triadic clique of girls, identified as a small scale hierarchy, was very exclusive in playing together and displayed great concern over being equal to one another; however, the notion of sameness as fairness was only applied to children within their clique. Vygotsky (1978) states while role playing sisters,

\footnotetext{
...'My sister and I act the same, we are treated the same, but others are treated differently.' ...the emphasis is on the sameness of everything that is connected with the child's concept of a sister; as a result of playing, the child comes to understand that sisters possess a different relationship to each other than to other people (p. 95).
}

When a child from outside the hierarchy, attempted to enter the girls' play, they were reminded of the unspoken rules of sisterhood. This was typically displayed as relational aggression. Field notes documented one such account when "Sarah attempted to enter their [Julie and Angela's] play by getting on her knees [O.C. showing that she was willing to accept the role of a baby]. Angela said, 'Here is the baby.' Julie said, 'No, we are not playing that' and proceeded to leave the area. Angela followed." This example is consistent with the research of Ostrov and Keating (2004) suggesting that girls are more concerned with relationships; therefore, implementing relational aggression tactics to establish social acceptance or status diffusion is prominent.

Another example was documented when Anne tried to initiate play with the girls and Angela ignored her. Then, Julie arrived and Angela immediately left the area to greet Julie. She returned to her work and held one of the animals in the air saying "Julie, Julie." Julie came to the block area and the two started playing while Anne was then engaged in parallel play.

Anne: Guys, here is another sister.

Julie: We don't need one. That is no fair.

Anne: But I don't need some.

Julie: We need one more for Angela. No, I mean we don't need one. We are bigger.

(O.C. Anne returned to parallel play. Angela and Julie continued to play together with two animals (cows) on the blocks).

Julie: Can you [Angela] have the mom and I have the sister?

Angela: Yeah. That is fair isn't it?

Julie: Yeah. Really fair.

Angela: Hey, we are not playing with you. (O.C. Angela looks at me after she says this, but I ignore her and contin ue to take notes).

Anne: But I am playing.

Angela: Play horses.

(O.C. Angela and Julie return to their play excluding Anne).

Of interest in the above documentation, is the fact that Julie and Angela were so concerned with being fair to each other yet lacked the ability to take into consideration Anne's feelings of being excluded. This confirms their sense of exclusiveness within their hierarchy while exemplifying the use of relational aggression to maintain their cohesiveness.

Another excerpt from the field notes, documents a clear example of how Julie and Angela's desire for sameness often overruled their ability to perceive fairness through the eyes of the other child. In this scenario, the children were playing in the dramatic play area and there was a vase of artificial Gerbera daisies on the kitchen table. There were three flowers in the vase, one of which had a broken stem yet appeared whole. Angela and Julie tried to grab the flowers off the table, but Alisha noticed. So, she grabbed a flower. Each girl had one flower; however, Angela had picked the broken one. Interestingly, Julie 
threatened to leave the area if the play did not go as she and Angela wished.

Angela: We only want one, please.

Alisha: No, you can share that.

Angela: Julie needs one.

Julie: Or we won't play here anymore.

Angela: Let me have it. This one is perfect.

(O.C. Angela had the broken flower and wanted the second flower that was not broken. This would have left Alisha with the broken flower).

Alisha: No. We can all have one that is fair.

Alisha did not want to be left with the broken flower, so she used assertive words and stood up for herself. She realized that everyone had one flower each which really was fair. However, through the eyes of Julie and Angela this was most likely not perceived as fair because they did not have the same flower. This example demonstrates both emergent themes, The Power of Exclusiveness through the eyes of the children in the hierarchy and The Power of Exclusion through the eyes of the child outside of their hierarchy.

\section{Discussion}

Early childhood provides an optimal time for young children to learn and practice social skills while in peer groups. It is imperative that adults support and encourage young children's social interactions with positive guidance. Children with a mentor, such as a teacher or coach, who support efforts through encouragement and belief, were identified as having higher resilience than those without mentors (Walsh, 2003 as cited in Keown, S., Carroll, R. and Raisor, J. M., 2020). Adults should be aware of the social dynamics in the classroom and be knowledgeable of positive guidance strategies which assist young children in negotiating and problem solving in peer groups. In the described study, the core staff members were aware of the existing social dynamics within the classroom, but not the complexity of the interactions; therefore, unable to fully assist the children in practicing negotiation skills. Rarely do staff members have the opportunity to step out of the teaching role and to observe the children's interactions. Active listening to the children's natural interactions during times when the children have a choice in what they are doing and with whom they are interacting is imperative to understanding the social dynamics within a classroom. Focus on the times when a child identified as a "leader" is absent. What happens to the social structure? Do other children step up to fulfil the role or does it remain vacant? Since not all the children in a classroom want to be leaders or are leaders of social groups, focus on their roles. Are they assigned or chosen? Is the child accepting of the role and fulfills it willing? If not, assist the child in learning how to approach the situation and negotiate a different space within the social structure. Future studies should focus on exploring these suggestions further. Additionally, this study should be replicated in a setting where the children do have a shared history. The skills learned in early childhood are truly the foundation for later competencies and interpersonal successes and most deserving of our time and attention.

\section{Implications for Practice}

This study authenticates the importance of teacher/ staff interactions with children in peer groups. Teachers should be aware of the social dynamics occurring in his/her classroom as this becomes a rich context for teachers to learn about individual children's social skills, temperament, interests and the like. Gallagher et al. (2007) state teachers should be "aware of a variety of social factors including classroom peer groups, children's placement in the social structure, social dominance hierarchies, identification of children in key social roles..." (p. 35-36). In the present study, for example, one of the core staff members expressed concern over a group of girls in the classroom who always seemed to be together. She stated, "...there tends to be some cliques, some groups, especially with some of the girls and I was really trying hard not to break them up, but kind of get them to join other groups and work there..." Gallagher et al. (2007) emphasize the importance of a teacher being aware of social dynamics within his/her classroom in order to provide a safe environment for all children, while also allowing children the space to construct their own social rules in order to advance cognitive abilities and social skills.

Staff members must be tuned into the children's cliques in order to observe aggression that might occur. The staff should be knowledgeable of physical as well as relational aggression and how to appropriately address such situations. For this reason, areas of high social interaction, such as the dramatic play area and the block area, should have increased adult supervision. In addition, considering the limited verbal capabilities of young children, the staff should model appropriate language such as the use of assertive words for the children. Teacher training programs, therefore, should emphasize development of teachers' capacity to "read" children's play (Zhulamanova \& Raisor, 2020).

The manner in which the staff was able to assist the children in directing the play of others as well as negotiating roles was highlighted throughout this study. This is a true exemplar of balance in the adult's skill to be able to intervene when necessary yet not dominate the children's play. The staff can serve as 


\section{iejee}

an invisible hand (Cairns \& Cairns, 1994; Farmer 2000 as cited in Gallagher et al., 2007) to scaffold and guide children's interactions (Gallagher et al., 2007). Gallagher et al. (2007) says, "Teachers can scaffold and guide children in new interactions and relationships in ways that unobtrusively foster productive relationships and social roles" (p. 18). The staff in the present study encouraged and modeled prosocial strategies such as problem solving, negotiation, and I-messages with the children and in doing so emphasized the importance of making individual choices and the children becoming more assertive with individual needs and wants. The staff should be aware of what the children are doing and be prepared with positive guidance strategies to implement when needed. With the guidance of an adult, children must learn how to take ownership of their actions by working through problems with their peers while in a safe classroom.

\section{References}

Bodrova, E. \& Leong, D. J. (2007). Tools of the mind: The Vygotskian approach to early childhood education. Pearson Merrill Prentice Hall.

Bogdan, R. C. \& Biklen, S. (2007). Qualitative research for education: An introduction to theories and methods (5th ed.). Boston, MA: Allyn and Bacon.

Cairns, R. B., \& Cairns, B. D. (1994). Lifelines and risks: Pathways of youth in our time. Press Syndicate of the University of Cambridge.

Copple, C. \& Bredekamp, S. (Eds.). (2009). Developmentally appropriate practice in early childhood programs (3rd ed.). National Association for the Education of Young Children.

Crick, N. R., Ostrov J. M., Burr, J. E., Cullerton-Sen, C., Jansen-Yeh, E., \& Ralston, P. (2006). A longitudinal study of relational and physical aggression in preschool. Applied Developmental Psychology, 27, 254-268.

Fabes, R. A., Martin, C. L., \& Hanish, L. D. (2009). Children's behaviors and interactions with peers. In K. H. Rubin, W. M. Bukowski, \& B. Laursen (Eds.), Handbook of peer interactions, relationships, and groups (pp. 45-62). The Guilford Press.

Farver, J. A. M. (1996). Aggressive behavior in preschoolers' social networks: Do birds of a feather flock together? Early Childhood Research Quarterly, 11, 333-350.

Fiske, S. T., \& Taylor, S. E. (1991). McGraw-Hill series in social psychology. Social cognition (2nd ed.). Mcgraw-Hill Book Company.
Gallagher, K. C., Dadisman, K., Farmer, T. W., Huss, L., \& Hutchins, B. C. (2007). Social dynamics of early childhood classrooms: Considerations and implications for teachers. In O. N. Saracho \& B. Spodek (Eds.), Contemporary perspectives in early childhood education (pp.17-48). Information Age.

Giles, J. W. \& Heyman, G. D. (2005). Young children's beliefs about the relationship between gender and aggressive behavior. Child Development, 76(5), 107-121.

Hartup, W. W. (2009). Critical issues and theoretical viewpoints. In K. H. Rubin, W. M. Bukowski, \& B. Laursen (Eds.), Handbook of peer interactions, relationships, and groups (pp. 3-19). The Guilford Press.

Keown, S., Carroll, R. and Raisor, J. M. (2020). Creating a community of caring within the school. International Electronic Journal of Elementary Education 12(4) 401-404.

Martin, C. L., Fabes, R. A., Hanish, L. D., \& Hollenstein, T. (2006). Social dynamics in the preschool. Developmental Review, 25, 299-327.

Maxwell, J. A. (2005). Qualitative research design: An interactive approach (2nd ed.). Sage Publications.

Miles, M. B. \& Huberman, A. M. (1994). Qualitative data analysis: An expanded sourcebook. (2nd ed). Thousand Oaks, CA: Sage.

Murray-Close, D. \& Ostrov, J. M. (2009). A longitudinal study of forms and functions of aggressive behavior in early childhood. Child Development, 80(3), 828-842.

Ostrov, J. M., \& Crick, N. R. (2007). Forms and functions of aggression during early childhood: A shortterm longitudinal study. School Psychology Review, 36(1), 22-43.

Ostrov, J. M., \& Keating, C. F. (2004). Gender differences in preschool aggression during free play and structured interactions: An observational study. Social Development, 13, 255-277.

Power, T. G. (2000). Play and exploration in children and animals. Lawrence Erlbaum Associates.

Raisor, J. (2010). A qualitative examination of social hierarchies among young children [Doctoral thesis]. 
Rhodes, M. (2012). Two Intuitive Theories Shape the Development of Social Categorization. Child Development Perspectives, The Society for Research in Child Development DOI: 10.1111/ colep.12007.

Rutland, A., Killen, M., \& Abrams, D. (2010). A new social-cognitive development perspective on prejudice: The interplay between morality and group identity. Perspectives on Psychological Sciences, 5, 279-291.

Stake, R. E. (1995). The art of case study research. Thousand Oaks, CA: Sage. *The Center. Retrieved July 12, 2009, from [removed to maintain confidentiality].

Thomsen, L. (2019). The developmental origins of social hierarchy: how infants and young children mentally represent and respond to power and status. Current Opinion in Psychology, 33, 1-8.

Vygotsky, L. (1978). Mind in society: The development of higher psychological processes. Harvard University Press. Penguin Books.

Walsh, F. (2003). Family resilience: A framework for clinical practice. Family Process, 42, 1-18. Wong, B. Y. L., (2003).

Zhulamanova, I. \& Raisor, J. (2020). Early Childhood preservice teachers' perceptions on children's play. International Online Journal of Primary Education, 9 (2). 